\title{
Effect of rice husk ash properties on the early age and long term strength of mortar
}

\author{
Binyamien I. Rasoul, Friederike K. Günzel and M. Imran Rafiq \\ School of Environment \& Technology, University of Brighton, UK \\ email: B.Rasoul@brighton.ac.uk; f.k.gunzel@brighton.ac.uk; \\ M.Rafiq@brighton.ac.uk
}

\begin{abstract}
This paper presents an experimental study on the effect of chemical composition and physical properties of rice husk ash (RHA) on the strength of mortar. The aim of this investigation was to establish the optimal RHA replacement levels as blending component in cement. Four different types of RHA (A, B, C and D) were used of which RHA-C and D had the highest content of amorphous silica. Compressive and tensile strength and workability of the mixes were compared with control OPC samples. Results show that the early age (7days) strength of RHA blended mortar samples was lower than the compressive and tensile strength of the OPC control samples. However, the 28 day strength of samples with up to $20 \%$ RHA-C and RHA$\mathrm{D}$ was higher than that of the control samples. The 90 day strength of all blended samples with up to $40 \%$ RHA was higher than that of the control samples. RHA-D performed best in the experiments with a compressive strength increase of $16 \%$ at $20 \%$ RHA replacement and an increase of compressive strength of $8.6 \%$ at $40 \%$ RHA replacement. The results at 90 days show that cement could be replaced with up to $50 \%$ RHA with only a small reduction in strength compared to OPC mortar. From the results it was found that the content of amorphous silica has the biggest influence on the strength of the mortar samples while the workability was higher for samples with finer grained RHA.
\end{abstract}

Keywords: Rice husk ash; silica content; pozzlanic activity; XRD analysis; compressive strength; tensile strength.

\section{INTRODUCTION}

Rice husk is a by-product of rice threshing; it can be used as fuel to generate electricity (Abedin and Das, 2014). The incineration process produces rice husk ash (RHA), which is about $25 \%$ of the weight of the husk. Rice husk incineration between $350^{\circ} \mathrm{C}$ to $750^{\circ} \mathrm{C}$ generally produces an amorphous form of silica, while crystalline silica is formed at temperatures over $800^{\circ} \mathrm{C}$ (Boating and Skeet, 1990). The pozzolanic property, low cost and wide availability of RHA has sparked interest to use the material for blending cement. 
The silica content, silica structure (amorphous to crystalline), fineness (specific surface area), and loss on ignition are the main factors influencing the reactivity of RHA. In turn they are directly related to the incineration temperature, incineration time and grinding duration. According too many authors (e.g. Givi et al., 2010), increasing the fineness of RHA particles leads to increased reactivity. Ismail and Waliuddin (1996) reported that finely ground RHA may improve the filler properties of crystalline silica. On the other hand, Mehta (1979, cited in Madandoust et al., 2011) reported that because the RHA derives its pozzolanic activity mainly from the internal surface area, grinding it to a high degree of fineness should be avoided. Currently there is no detailed explanation of the mechanism how the physical and chemical characteristics of RHA impact mortar strength at long term age and with high replacement ratio (Khana et al., 2014). The current study gives a comparative study to assess the pozzolanic reactivity of RHA by identifying the effect of physical and chemical properties of RHA on the strength of mortar at long term age. To reach these objectives, the grain size, chemical composition and pozzolanic properties of four different types of RHA (A, B, C and D) were determined.

\section{MATERIALS}

Cement: Ordinary Portland cement (OPC) CEM I 52.5N (BS EN 197-1: 1996) was used for all samples. The physical and chemical composition of cement is given in by the manufacturer (CEMEX UK Cement Ltd) and shown in Table1.

Table1: Physical and chemical properties of OPC (CEM I 52.5N)

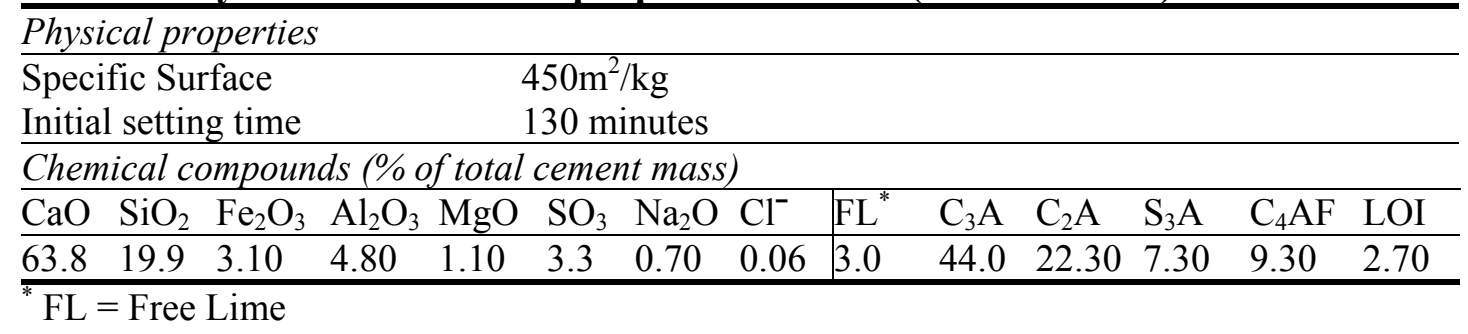

Rice Husk Ash: Three types of rice husk ash (A, B and C) were provided by Navdanya Food PVT LTD Odisha, India. RHA-D was produced by re-incinerating $\mathrm{RHA}-\mathrm{C}$ at $550^{\circ} \mathrm{C}$ for 6 hours. The particle size distribution and specific surface area were determined with a laser diffractometer Mastersizer 2000 particle size analyser. The chemical analysis for oxide composition of RHA was carried out by X-ray fluorescence. The physical and chemical properties of the RHA types are given in Tables 2 and 3.

Table 2: Physical properties of RHA types

\begin{tabular}{l|l|l|l}
\hline RHA type & $\begin{array}{l}\text { Specific surface area } \\
\left(\mathrm{m}^{2} / \mathrm{kg}\right)\end{array}$ & $\begin{array}{l}\text { Mean particle size } \\
(\mu \mathrm{m})\end{array}$ & Colour \\
\hline RHA-A & 537 & 23.397 & Grey \\
RHA-B & 587 & 20.948 & Dark Grey \\
RHA-C & 691 & 15.804 & Black \\
RHA-D & 808 & 12.640 & Light Grey \\
\hline
\end{tabular}


Table 3: Chemical composition of RHA types (\% of total weight)

\begin{tabular}{lllllccccccl}
\hline RHA type & $\mathrm{SiO}_{2}$ & $\mathrm{Al}_{2} \mathrm{O}_{3}$ & $\mathrm{Fe}_{2} \mathrm{O}_{3}$ & $\mathrm{CaO}$ & $\mathrm{MgO}$ & $\mathrm{Na}_{2} \mathrm{O}$ & $\mathrm{K}_{2} \mathrm{O}$ & $\mathrm{P}_{2} \mathrm{O}_{5}$ & $\mathrm{SO}_{3}$ & $\mathrm{MnO}$ & LOI* \\
\hline RHA-A & 92.10 & 1.07 & 0.24 & 0.72 & - & - & 1.37 & 0.40 & 0.08 & 0.11 & 3.80 \\
RHA-B & 89.31 & 1.39 & 0.39 & 0.99 & - & - & 1.81 & 0.75 & 1.10 & 0.17 & 5.10 \\
RHA-C & 84.30 & 1.07 & 0.18 & 0.73 & - & - & 1.52 & 0.68 & 0.08 & 0.14 & 11.35 \\
RHA-D & 93.49 & 1.19 & 0.20 & 0.97 & - & - & 1.59 & 0.66 & 0.08 & 0.12 & 1.65 \\
\hline
\end{tabular}

*LOI: Loss on ignition of rice husk ash at $975 \pm 25^{\circ} \mathrm{C}$ for 15 minutes according to EN 1962:1994

Fine aggregates (silica sand): Fine silica sand (SIBELCO) was used for the mortar mixes; according to the manufacturer the sand has a silica content of $99.73 \%$; the fineness modulus (BS EN 12620, 2002) was determined to be $\mathrm{FM}=1.5$ using the Mastersizer 2000 particle size analyser.

Superplasticiser: Auracast200 superplasticiser was used for all samples. According to the manufacturer (Fosroc), Auracast200 is a unique combination of the latest generation of polycarboxylate polymers.

\section{EXPERIMENTAL METHODS}

Electrical conductivity test for pozzolanic activity: The pozzolanic activity was determined by the method described in Luxan et al. (1989). Feng et al. (2004) confirmed the suitability of the method to determine the pozzolanic activity of rice husk ash. The method consists of two steps: initially, the electrical conductivity of a saturated calcium hydroxide solution is measured. This measurement is repeated after adding $5 \mathrm{~g}$ of RHA into $200 \mathrm{ml}$ of saturated calcium hydroxide solution at $40^{\circ} \mathrm{C}$ and stirring for two minutes. The difference between the initial and final conductivity is used as a measure of pozzolanic activity (Luxan et al., 1989).

X-ray diffraction analysis: The mineralogical analysis of RHA was carried out using X-ray diffraction with a PANalytical X'Pert Pro MPD, powered by a Philips PW3040/60 X-ray generator operating with a $40 \mathrm{kV}, 40 \mathrm{~mA} \mathrm{Cu}$ radiation sources and a Philips PW3040 diffractometer.

Mortar samples: Mortar samples were cast with all four types of RHA. The mix proportion for mortar according to ASTM C 270 type M, where water content (w/c) is 0.50 , cement $(\mathrm{c})=2200 /[(1+(\mathrm{w} / \mathrm{c})]+(\mathrm{s} / \mathrm{c})$, sand $(\mathrm{s})=2200-\mathrm{c}-\mathrm{w}$, sand to cement ratio 2.25 and the average density of the mortar $=2200 \mathrm{~kg} / \mathrm{m}^{3}$. OPC was replaced by $0 \%$, $5 \%, 10 \%, 15 \%, 20 \%, 30 \%, 40 \%$ and $50 \%$ (by weight) respectively. For the purpose of compressive strength tests, $50 \mathrm{~mm}$ cubes samples were cast and cured in water for 7, 28 and 90 days. For the tensile strength testing, small 'dog-bone' samples (76.20 mm length $\times 44.50 \mathrm{~mm}$ width $\times 25.4 \mathrm{~mm}$ depth) were cast and cured to the date of test (28 and 90 days). The workability of each mix was assessed using the flow table for mortar according to BS EN 12350-5. 


\section{RESULTS AND DISCUSSION}

Pozzolanic activity: The pozzolanic activity of the RHA types is shown in Table 4. RHA-A and RHA-B are interpreted as having 'variable pozzolanic activity' (Luxan et al., 1989) while RHA-C and RHA-D have high pozzolanic activity.

Table 4: The pozzolanic activity based on the electrical conductivity test result

\begin{tabular}{lllll}
\hline RHA Type & A & B & C & D \\
\hline Electrical conductivity change, $\Delta \sigma_{2 \min }(\mathrm{mS} / \mathrm{m})$ & 90 & 107 & 181 & 173 \\
\hline
\end{tabular}
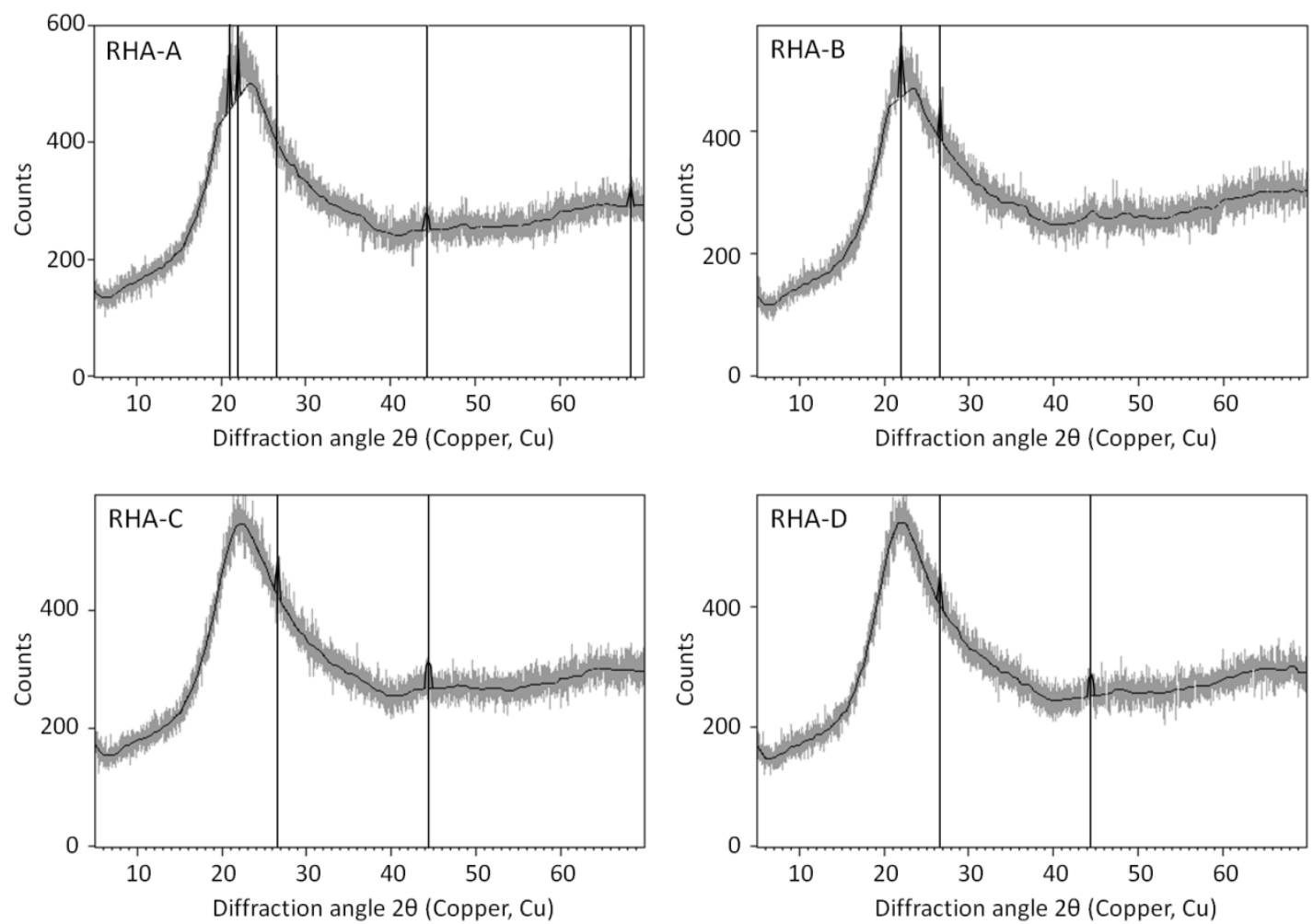

Figure 1: XRD results of all RHA types

Table 5: XRD Peak counts of RHA samples

\begin{tabular}{lllllll}
\hline & \multicolumn{7}{c}{ Counts at angles of $2 \theta$} \\
RHA type & $20.90^{\circ}$ & $21.93^{\circ}$ & $22.04^{\circ}$ & $26.70^{\circ}$ & $44.40^{\circ}$ & $68.40^{\circ}$ \\
\hline RHA-A & 116.4 & 86.6 & - & 104.4 & 21.8 & 35.2 \\
RHA-B & - & - & 89.3 & 116.7 & - & - \\
RHA-C & - & - & - & 37.7 & 20.3 & - \\
RHA-D & - & - & - & 52.4 & 18.1 & - \\
\hline
\end{tabular}

X-Ray diffraction (XRD) analysis: The XRD results are shown in Figure 1 and Table 5. The crystalline contents show as sharp peaks on top of the broad amorphous background; the results show a much higher crystalline content of RHA-A and RHAB while samples RHA-C and RHA-D have very little crystalline content. These results agree with the electrical conductivity test results. Based on the NIOSH Manual of Analytical Methods (NMAM, 2003) the peaks in the XRD results of RHA can be 
assigned to cristobalite at $21.93^{\circ}$, possibly cristobalite or tschernichite $\left((\mathrm{Ca}, \mathrm{Na})\left(\mathrm{Si}_{6 \mathrm{Al}}\right) \mathrm{O}_{16^{\circ}}{ }^{\circ}-8\left(\mathrm{H}_{2} \mathrm{O}\right)\right)$ at $22.04^{\circ}$ and quartz at $20.85^{\circ}$ and $26.7^{\circ}$. In RHA-A the mineral at $2 \theta=44.40^{\circ}$ may be identified as brownleeite $(\mathrm{MnSi})$, while the substance at $2 \theta=68.4^{\circ}$ is unknown.

Workability: The workability of all mortar samples is shown in Figure 2. The content of superplasticiser had to be increased for samples with high RHA content to keep the workability within an acceptable limit. Surprisingly the samples with the finer grain size RHA (type C and D, see Table 2) have a higher workability. This may be explained with higher water absorption in the pores of amorphous silica particles in the coarser RHA types. Bui (2001) concluded that the water reducing effect of superplasticizer is clearer in the mixtures containing RHA with comparatively high fineness.

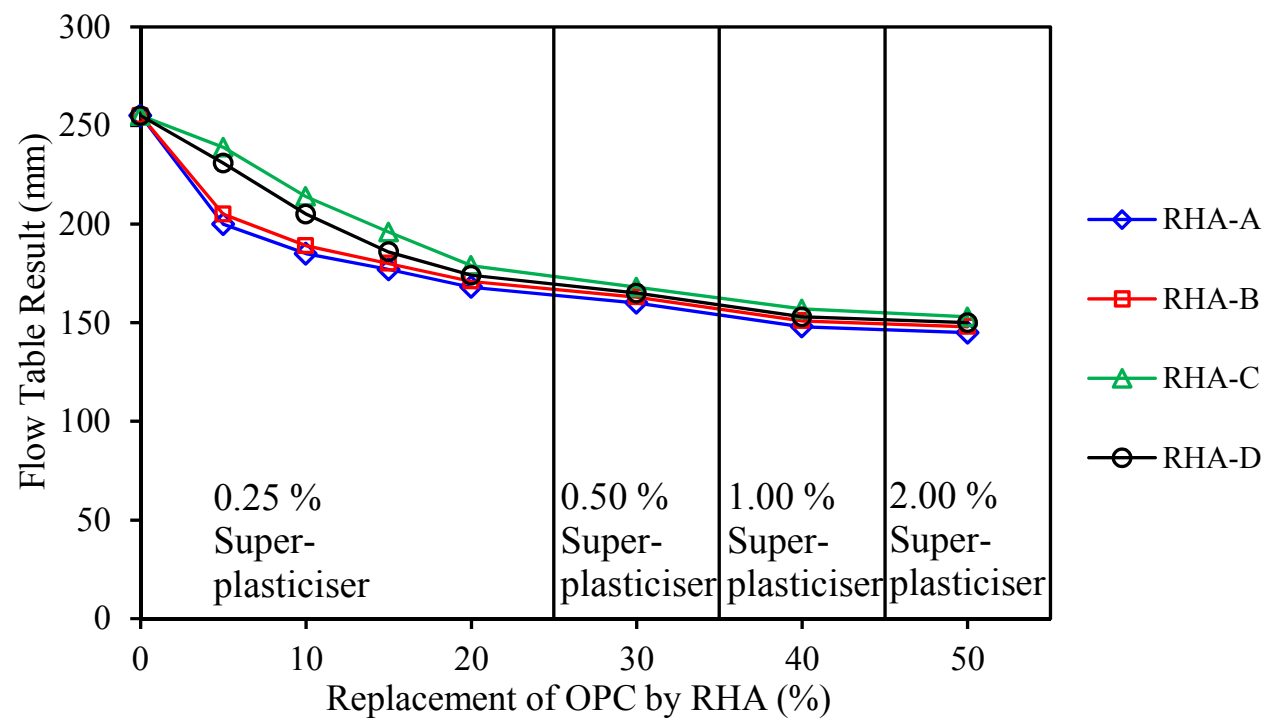

Figure 2: Workability of mortar samples (water:cement:sand $=0.5: 1: 2.25$ )

Compressive strength of RHA blended mortar: The compressive strength data (Figure 3) show that the 7 day compressive strength of nearly all RHA blended samples is lower than that of the control OPC mortar. At 28 days the results are mixed for replacements between $5 \%$ and $30 \%$, and all samples with replacement above $30 \%$ are weaker than the control mix. At 90 days the compressive strength of RHA-A starts low at 5\% RHA replacement but remains slightly above the control mortar strength for up to 40\% RHA replacement; at 50\% replacement the strength decreases sharply to a value below the control mortar strength. The compressive strength of RHA-B is similar as for RHA-A, but without the reduction in strength (compared to control sample) at 5\% RHA replacement. The compressive strength of RHA-C shows the highest strength of all RHA types at 5\%-15\% replacement and again at 50\% replacement; this result indicates that replacements up to $50 \%$ may be possible without compromising on the mortar strength. The compressive strength of RHA-D has a maximum at $20 \%$ replacement; at $40 \%$ the strength is still higher than that of the control sample. 


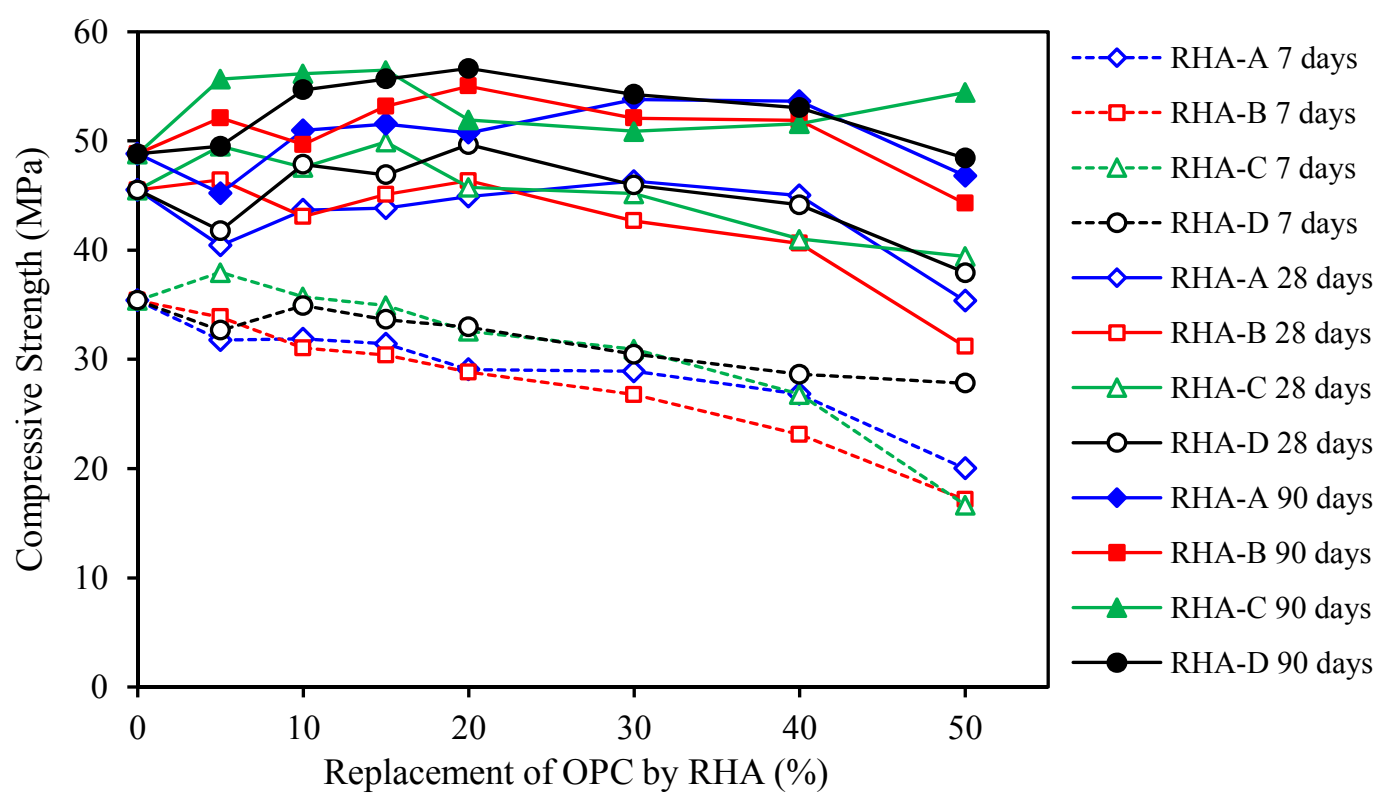

Figure 3: Compressive strength of control and RHA blended mortar

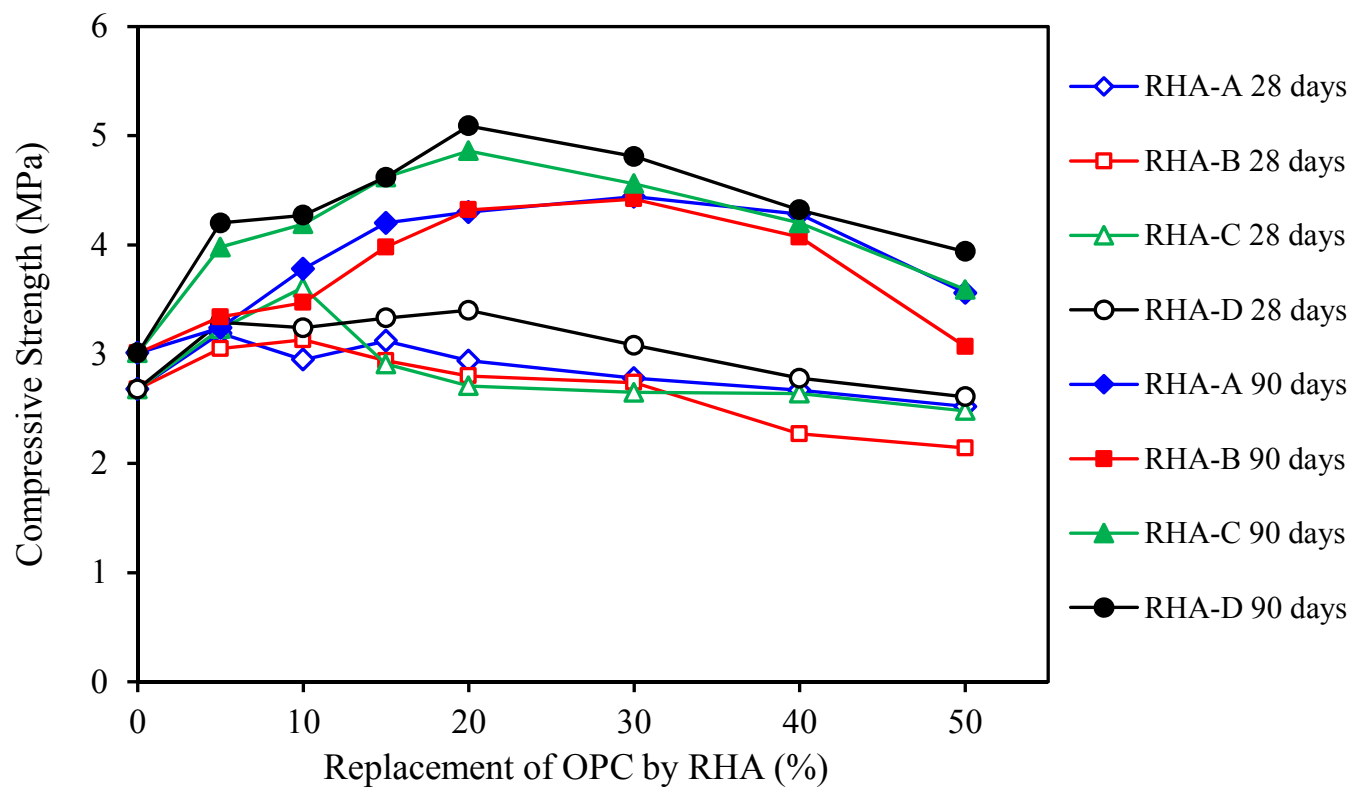

Figure 4: Tensile strength of control and RHA blended mortar

These results were different to the results of many authors; e.g. Marthong (2012) reported that the optimal limit of partially replacement of cement by RHA it is $10 \%$. Habeeb and Mahmud (2010) concluded that the compressive strength of blended mortar with $10 \%$ RHA is increased because of the pozzolanic activity and the micro filler effect of RHA. Based on the obtained results it can be said that the particle size (specific surface area) and silica structure (amorphous) have a larger influence on the mortar strength than overall silica content and loss on ignition (as in RHA-C). According to Nguyen (2011) the increase of RHA blended mortar strength is caused 
by absorption of water into the pores of RHA particles. When this adsorbed water at later age is released from inside of the pores to the surrounding cement matrix, it will cause the relative humidity in interior to remain high, so the hydration process can continue for longer.

Tensile strength of RHA blended mortar: The results of direct tensile strength are shown in Figure 4; it is found that the direct tensile strength behaved differently to the compressive strength. Especially at 90 days the tensile strength was up to $70 \%$ higher than that of the control sample. Overall, 20\% replacement of cement by RHA-C and D resulted in maximum tensile strength. Beyond 20\% replacement, the tensile strength decreases again but remains higher than that of the control sample. To date there is no explanation why the tensile strength increases so much more than the compressive strength and this is being further investigated.

\section{CONCLUSIONS}

- The strength of mortar blended with RHA depends mainly on the content of reactive (amorphous) silica rather than the overall silica content. A high specific surface area of the RHA also has a positive effect on the mortar strength.

- The increase in strength (compressive and tensile) of mortar with RHA containing a high amount of crystalline silica is better justified by the filler effect (physical) than by the pozzolanic effect (chemical). After depletion of all amorphous silica by reacting with calcium hydroxide $\left[\mathrm{Ca}(\mathrm{OH})_{2}\right]$ to produce secondary $\mathrm{C}-\mathrm{S}-\mathrm{H}$ gel, the remaining crystalline silica behaves as a filler resulting in an increased density of the mortar.

- As much as $50 \%$ by weight of OPC can be replaced by RHA-C even with a high loss on ignition (LOI $=11.35 \%$ ) without any adverse effect on the strength of mortar; this is attributed to the as a result of high reactivity of the amorphous silica and fine grain size.

- RHA-C was re-burned for 6 hours to create RHA-D. This reduced the loss on ignition from $11.35 \%$ to $1.65 \%$, increased the silica percentage from $84.30 \%$ to $93.49 \%$ and reduced the mean particle size from $15.8 \mu \mathrm{m}$ to $12.64 \mu \mathrm{m}$. This increase in the proportion of active silica and decrease of loss on ignition led to a rice husk ash (RHA-D) with high performance as shown in the results

- The results reveal that the mixtures with the finer grained rice husk ash exhibit higher workability compared to the coarser grained rice husk ash mixes. The phenomenon can be attributed to two factors; first, the porosity of the particles, where the finer grinding of RHA led to a reduction of water absorption; second, the crystalline silica behavior as a filler lead to an increased water demand, which in turn reduced the workability of the mixtures.

- The optimal replacement level of cement by RHA depends more on the silica structure (amorphous) and particle size than overall silica content of RHA (example RHA-C).

- High carbon content (loss on ignition) does not preclude a high performance of blended cement mortar when the silica in the RHA is amorphous as it is observed with RHA-C. 


\section{REFERENCES}

Abedin, M.R., and Das, H.S. (2014). "Electricity from Rice Husk: A Potential Way to Electrify Rural Bangladesh." International Journal of Renewable Energy Research (IJRER), 4(3), 604-609.

Boateng, A.A., and Skeete, D.A. (1990). "Incineration of rice hull for use as a cementitious material" the Guyana experience. Cement and Concrete Research. 20(5), 795-802.

British Standards Institution (2002). Aggregates for Concrete. BS EN 12620. London.

British Standards Institution (1996). Cement - Part1: Composition, specifications and conformity criteria for common cements. BS EN 197-1. London.

British Standards Institution (2000). Testing fresh concrete - Part 2: Slump-test. BS EN 12350-2. London.

Bui, D.D. (2001). Rice husk ash a mineral admixture for high performance concrete. TU Delft, Delft University of Technology.

Feng, Q., Yamamichi, H., Shoya, M. and Sugita, S. (2004). "Study on the pozzolanic properties of rice husk ash by hydrochloric acid pretreatment." Cement and Concrete Research, 34(3), 521-526.

Givi, A.N., Rashid, S.A., Aziz, F.N.A., and Salleh, M.A.M. (2010). "Assessment of the effects of rice husk ash particle size on strength, water permeability and workability of binary blended concrete." Construction and Building Materials, 24(11), 2145-2150.

Habeeb, G.A., and Mahmud, H.B. (2010). "Study on properties of rice husk ash and its use as cement replacement material." Materials research, 13(2), 185-190.

Ismail, M.S., and Waliuddin, A.M. (1996). "Effect of rice husk ash on high strength concrete." Construction and building materials, 10(7), 521-526.

Khana, M., Jamil, M., Karimc, M., and Zaind, M. (2014). "Strength and Durability of Mortar and Concrete Containing Rice Husk Ash. A Review." World Applied Sciences Journal, 32 (5), 752-765.

Luxán, M.D., Madruga, F., and Saavedra, J. (1989). "Rapid evaluation of pozzolanic activity of natural products by conductivity measurement." Cement and concrete Research, 19(1), 63-68.

Madandoust, R., Ranjbar, M.M., Moghadam, H.A., and Mousavi, S.Y. (2011). "Mechanical properties and durability assessment of rice husk ash concrete." Biosystems engineering, 110(2), 144-152.

Marthong, C. (2012). "Effect of rice husk ash (RHA) as partial replacement of cement on concrete properties." International Journal of Engineering Research and Technology, Vol. 1, No. 6. ESRSA Publications.

Nguyen, V.T. (2011). Rice husk ash as a mineral admixture for ultrahigh performance concrete. PhD Dissertation, Delft University of Technology.

NIOSH Manual of Analytical Methods (NMAM). (2003). "Silica, crystalline, by XRD: method 7500." 4th edition, Issue 4.

Standard, A.S.T.M., 2005. C270, Standard specification for mortar for unit masonry. 